\title{
New Training Model of School-Enterprise Cooperation for Professional Postgraduates
}

\author{
Ou Shifeng, Gao Ying*, Jiang Peihe \\ School of Optoelectronic Information Science and Technology, Yantai University, Yantai, China \\ Email address: \\ ousfeng@126.com (Ou Shifeng), claragaoying@126.com (Gao Ying), jiangpeihe@163.com (Jiang Peihe) \\ ${ }^{*}$ Corresponding author
}

\section{To cite this article:}

Ou Shifeng, Gao Ying, Jiang Peihe. New Training Model of School-Enterprise Cooperation for Professional Postgraduates. Science Journal of Education. Vol. 9, No. 1, 2021, pp. 20-26. doi: 10.11648/j.sjedu.20210901.14

Received: February 8, 2021; Accepted: February 27, 2021; Published: March 3, 2021

\begin{abstract}
Under the new situation, the cultivation of high-level professional postgraduates with both innovative and practical ability has become a key issue to be solved urgently in current graduate education. Professional postgraduates are different from academic postgraduates, and their training methods should also be different from academic postgraduates. This research analyzes the reasons for the problems and shortcomings of the current professional postgraduates training model in the school-enterprise cooperation model, and provides a new and effective training model for professional postgraduates school-enterprise cooperation based on engineering projects. Based on the vision of collaborative innovation and collaborative training, this study summarizes the practical problems and international experience of the training mode of professional postgraduate. Relying on the existing engineering conditions and practice environment of disciplines, schools and cooperation units, through the establishment of school enterprise collaborative innovation group, this paper puts forward the school enterprise collaborative training mode of professional postgraduate with engineering project as the carrier, from three aspects of adhering to the engineering project as the carrier, adhering to the interactive training process, and adhering to the team collaborative training research, social services and other integrated cooperation framework provide macro response ideas, micro solutions and operational implementation path for collaborative innovation training. Through the clear school enterprise cooperation project, this new training effectively collects the resources and elements of universities and enterprises, and realizes the effective collaboration of school enterprise cooperation in cultivating applied innovative talents.
\end{abstract}

Keywords: School-enterprise Cooperation, Professional Postgraduates, Talent Training Model, Practice Ability

\section{Introduction}

Under the background of knowledge explosion era, the quality of training high-level talents in China has been unable to meet the needs of social and economic development. Nowadays, graduate students not only need to have professional theoretical knowledge, but also need to exercise more practical and innovative ability. Graduate education is gradually undertaking the important task of cultivating applied and innovative talents [1]. However, at present, the training mode of professional postgraduates is still relatively single, lacking a set of mature and effective practice system, and there are still many imperfections in the training process, curriculum, tutor team construction and other aspects, which have seriously restricted and affected the healthy development of postgraduate education. Therefore, the reform and innovation of the current training mode of master's degree has become an urgent problem to be solved.

Although the Chinese government recognized the importance of cultivating professional postgraduates with practical ability as early as 2009, and began to recruit professional postgraduates. However, judging from the preliminary training results in recent years, the practical and innovative abilities of professional postgraduates have no obvious advantages compared with academic postgraduates. The main reason is that there is no effective training mode specifically designed for the characteristics of professional postgraduates. The training mode of academic postgraduates is still used, and the teaching practice is a formality [2].

In recent years, in order to solve the existing problems of professional postgraduate training mode, a lot of research has been carried out. Through the cooperation of the combination 
of science and education, the integration of industry and university, the cooperation between school and enterprise, literature [3] puts forward a three-party cooperative education mode. Through the analysis of the main problems existing in the cultivation mode of optical engineering graduate students in literature [4], the corresponding countermeasures are given from the aspects of strengthening the examination and evaluation of degree points, strengthening the cultivation quality and characteristics of enrollment units, and clarifying the cultivation direction of graduate students. Taking the reform and innovation of the training mode of full-time professional master degree in forestry of Gansu Agricultural University as an example and focusing on the goal of cultivating talents meeting the needs of society and forestry industry, literature [5] analyzes the actual effect of the reform and practice of the training mode of full-time professional master degree in forestry of Gansu Agricultural University, and discusses the innovation mechanism of full-time forestry master degree in talent training orientation and goal, curriculum system construction, practice teaching and evaluation and supervision system. Through the reform and teaching practice of professional degree application-oriented talents training system, literature [6] constructs a talent training mode that closely combines graduate students' innovation and entrepreneurial ability. In order to solve the problems of great resistance in the current professional practice reform, unstable school enterprise cooperation mode, and imperfect system guarantee system, literature [7] puts forward the methods of carrying out engineering master's professional practice under the mode of industry education integration from the aspects of establishing a new type of cooperative relationship, promoting the docking of the needs of both sides, and the government's overall support, and puts forward some suggestions on the refinement of the training system. According to the problems exposed in the training process of full-time master of engineering, the training mode is discussed in literature [8], which is mainly optimized from the aspects of curriculum, teaching method improvement, professional practice, tutor structure, academic paper writing and evaluation. Taking the cultivation of master of engineering management as an example, literature [9] discusses the cultivation mode of industry education integration to cultivate professional degree postgraduates, analyzes the plan, implementation, inspection and evaluation, feedback and correction of industry education integration in the cultivation process, so as to dynamically adapt to the cultivation needs and realize the cultivation goal of high-level compound application-oriented talents. The above research has played a great role in enriching and improving the training mode of professional postgraduates, but they have insufficient research on the practical ability and problem-solving ability of postgraduates. In the aspect of applied talents training, we need to do more research and practice.

After World War II, the cultivation and education of practical and applied postgraduates has become the main body of American master level education. Driven by the new economic policy, American colleges and universities pay more attention to the cooperation with the business community in order to cultivate high-level professionals more suitable for the development of enterprises [10, 11]. At this time, the collaborative training mode of University and enterprise joint training of graduate students appeared. The most typical case of this mode is the "Silicon valley mode" formed by Stanford university and industry. The training goal of collaborative training mode is to cultivate applied and development-oriented research talents. The most prominent feature of its training process is that it emphasizes the technical research combined with the actual production problems, so as to realize the unity of curriculum, scientific research and production practice. Cooperative training also requires universities and enterprises to work out training plans together [12]. The cooperation between universities and enterprises usually takes the form of establishing "university enterprise" joint research center, signing scientific research cooperation agreement, and making cooperation plans. In terms of tutor guidance, the collaborative training mode adopts the way of joint guidance by the steering committee. In the process of learning, scientific research and practice, graduate students receive not a single tutor, but the collective guidance of tutors. The steering committee is fully responsible for guiding the learning, scientific research and practice of graduate students, and the work of tutors runs through the whole process of graduate cultivation. This kind of collaborative training mode in foreign countries provides us with experience to learn from in terms of talent training concept, training process, tutor guidance and so on.

This article will focus on the discussion and analysis of the existing problems in the current professional postgraduates training model, and on this basis, explore a new school-enterprise cooperation training model based on engineering projects.

\section{The Current Model of School-enterprise Cooperation in Training Professional Postgraduates}

In order to improve the practical ability of professional postgraduates, the training mode adopted by colleges and universities is mainly school-enterprise cooperation mode. School-enterprise cooperation refers to the process in which schools and enterprises jointly cultivate talents according to the consensus reached. School owners should guide and urge students to complete the accumulation of basic knowledge required by the state, while enterprises should ensure students to exercise their practical ability. Both partise share relevant resources and superior achievements when cultivating talents.

The current school-enterprise cooperation model mainly adopts the dual main structure, the current school-enterprise cooperation model mainly adopts a dual main body structure. The school has reached an agreement with the enterprise to list the $" \times \times$ School Social Practice Base" in the enterprise, 
allowing students with a certain knowledge base to go to the enterprise through social practice. This kind of social practice is usually limited to summer and winter vacations and is linked to credits. Students often just want to get the corresponding credits and neglect the cultivation of their own professional skills and practical ability. Facts show that if students practice for less than half a year, then the effect of improving students' practical ability in the form of social practice is not ideal. We will make a concrete analysis below.

\section{Reasons for the Unsatisfactory Effect of the Current Training Model for Professional Postgraduates}

First of all, the enterprises do not recognize the current school-enterprise cooperation model. As an enterprise, its main goal is to maximize profits, while the main goal of a school is to cultivate talents with higher academic level for the country. The goals pursued by the two are essentially different. Students' learning and enterprises' social production are sometimes contradictory. To cultivate students with practical ability means to pay extra training costs for enterprises. Moreover, the school-enterprise cooperation model in reality is difficult to bring more competitive advantages to the development and interest pursuit of enterprises. On the one hand, if students practice in enterprises for less than half a year, it is not easy to require enterprises to provide suitable short-term jobs for the students, because enterprises need to spend energy in a short time to complete the cultivation of students' practical ability is not conducive to their pursuit of the goal of profit maximization; On the other hand, fewer students who have been trained in enterprises choose to stay in the enterprises for development [2]. Enterprises spend human and financial resources to cultivate talents for the school and the society. However, after students finish their practice, how to arrange the work undertaken by them is also a problem faced by enterprises. If there is no national rigid regulations and policy support, but only for the society and the school to cultivate high-level graduate students with practical ability, for this "LeiFeng-style" school-enterprise cooperation model, the attitude of most enterprises is that they can not participate without participating, less participation can be achieved with less participation, which leads to low recognition and participation of the current school-enterprise cooperation in training graduate students. Many enterprises are unwilling to cooperate with schools to cultivate the students' practice ability. Even if they are willing to cooperate, it is only a symbolic and shallow level of cooperation. Students are arranged to do simple tasks without involving the core technology of the company. Some companies even enroll students in the name of providing social practice opportunities to do some simple and mechanical work, the purpose of which is to obtain free or cheap labor. At the same time, in order to protect their own intellectual property rights and prevent the disclosure of core production technology, the degree of openness to students is not high. This makes it difficult for graduate students to truly engage in some work related to their majors and effectively improve the theoretical level and practical ability learned [13, 14].

Secondly, school learning is separated from corporate practice. What students learn at school is disjoined from what they practice in enterprises, which results in that teaching and practice not mutually complementary. The current school-enterprise cooperation model is to allow students to learn relevant theoretical basic knowledge in school, and then go to the enterprise to exercise their practical ability. This training mode is vulnerable to the limitations of school teaching level, it is difficult to keep up with the requirement of the enterprise. As a result, students may not already have the professional theories and professional skills for the work they are engaged in at the beginning of practice, which requires enterprises to train students to meet the needs of work can show the corresponding practical work. The separation of teaching and practice makes it impossible for students to apply the professional theoretical knowledge learned in school to the actual work of the enterprise. This is also the main reason for the low efficiency of the current school-enterprise cooperation model. In addition, school teaching is mainly based on professional boundaries. Teachers teach students mainly single-disciplinary knowledge, rarely involving the cross-application of multiple disciplines, and the practice of enterprises is mainly based on actual problems encountered in engineering. Where there are many interdisciplinary content, which requires multi-disciplinary theories, so students' practical ability is very limited.

Finally, there is no effective carrier for school-enterprise cooperation at this stage. The current school-enterprise cooperation often does not have a clear carrier, the practice process of students in enterprises is mainly a kind of workers to participate as a kind of migrant worker, which is not conducive to better exerting the students' subjective initiative. Students practice in enterprises only to complete practical tasks, but not through the practice in enterprises to test the theoretical knowledge in school teaching and improve their practical ability. Moreover, the school-enterprise cooperation relationship under the traditional model is not deep. The way schools establish social practice bases in enterprises is mostly just a shallow and symbolic cooperation. This kind of cooperation can only help professional postgraduates to achieve social practice. The credits do not really allow students to participate in the practice, so it does not enable enterprises, schools and students to truly benefit from the practice process and achieve "multi-wins"[15].

\section{Thoughts on the New Training Model of Professional Postgraduate}

According to the actual situation of professional postgraduate training in China, this achievement puts forward the school enterprise collaborative training mode with engineering project as the carrier, which provides a new idea for the reform and innovation of professional postgraduate 
training mode emphasizing practical ability. Under the guidance of the concept of collaborative innovation, colleges and enterprises jointly establish a school enterprise collaborative innovation organization -- school enterprise community; the school enterprise community establishes a project team based on a clear school enterprise cooperation project; the project team designs various training links based on the needs of the project; the whole process and collective training of the project team are adopted, and the teaching and research of the course are carried out according to the requirements of the course This paper studies the training process of practice interaction and integration, which is a talent training mode of professional postgraduate. Compared with the base cooperation mode, the project cooperation mode has the characteristics of unitary subject training, whole process collective training of project team, interactive integration of course learning and research practice.

The collaborative mode of the project includes two core connotations, one is to take the project as the carrier, the other is the whole process collaborative training between school and enterprise. Through these two main ways, the collaborative mode of engineering project can achieve the goal of professional postgraduate training.

Taking engineering project as the carrier is to build the training mode based on the needs of school enterprise cooperation project. Each link of the training process is designed based on the needs of the actual engineering project: the postgraduate enrollment plan is not assigned to the discipline or tutor, but directly assigned to the project team based on the needs of the project; the selection of students is jointly determined by the project team under the premise of meeting the policy; the proportion of compulsory courses and theoretical courses in the curriculum system design is greatly reduced, and the practical courses and project courses are based on the engineering project Objectives need to be set, and the proportion can be increased; practice courses and project courses are taught by the project team independently; the teaching method of "problem-based learning" is adopted, in which the problem is the specific problems encountered in the completion of the project; the course teaching teachers and instructors are the project team; the content of dissertation research (Thesis) is the work content of the project. The training mode based on engineering project can achieve three effects. First of all, taking the project as the carrier of training graduate students can make the tutor team have the focus of cooperative training, and the team training will not become a mere formality; second, it realizes the virtuous circle of graduate students' learning in project practice, project completion in graduate students' learning, and the integration of graduate training and project practice. More importantly, taking the engineering project as the carrier, the graduate students have a dual identity, they are not only students, but also workers to complete the project, which realizes the intention of students to study in the real working situation as workers.

Collaborative training is the training mode of school enterprise cooperation dimension. The purpose is to break the organizational boundaries between colleges and enterprises, fully release the vitality of talents, capital, information, technology and other elements between colleges and enterprises, and improve the quality of personnel training. The whole process training is the training mode of graduate training process dimension, which starts from the formulation of graduate training objectives, runs through all aspects of graduate training, and finally achieves the goal of graduate training. The whole process of school enterprise collaborative training is that in the whole process of postgraduate training, universities and enterprises work together to cultivate talents through systematic coordination and cooperation, resulting in a "1 $+1>2 "$ talent training synergy effect. The whole process of school enterprise collaborative training includes two meanings: the first is the cooperation of training subjects, which realizes the cooperation of colleges and enterprises in the main level of talent training by establishing a school enterprise community. The school enterprise community is formed by the mutual penetration of universities and enterprises and the high integration of resources. Different from the base type of school enterprise cooperation, it has a fixed site, organization, unified rules, objectives, systems, is an independent organization. At the same time, it also has the attributes of university education and enterprises producing benefits through the development of production technology. Through the research and development of cooperative projects, the school enterprise community can realize the fundamental demands of both sides. Taking the school enterprise community as the main body of training makes the school enterprise cooperation training talents no longer seem to be in harmony; the second is the cooperation of the training process. The cooperation in the training process includes school enterprise joint determination of cooperative engineering projects, joint use of their own resources to form project teams, joint recruitment and selection of project teams, joint development of graduate training objectives and standards, joint research and development of training programs, joint undertaking of graduate course teaching and practical training tasks, joint Research of teaching organization forms and teaching methods, and joint guidance Graduate project or dissertation, etc.

The research is based on the actual project, equipment and financial advantages of the enterprise, and with the help of the forward-looking vision of the tutors inside and outside the school and the prior understanding of the students' actual ability, select the appropriate enterprise to lead the students to enter the jobs that help to improve their professional skills, realize the complementation of production, learning and research, so as to complete the technological transformation of the enterprise and the development of new products, so as to make the scientific and technological innovation more effective Achievements are directly transformed into productive forces. For the professional degree personnel training mode guided by engineering projects, first of all, projects can come from enterprises, or joint development between schools and enterprises. Secondly, according to the characteristics of the project, the tutor can select the students 
suitable for the project from the beginning of enrollment; at the same time, in the process of pre graduate training in school, the tutor can not only understand the students, but also recommend the positions that can be engaged in to the enterprise according to the characteristics of the students, so that the enterprise can better allocate talents reasonably. In addition, according to the needs of the project itself, the tutor can flexibly adjust the focus of the students' courses in school, so as to meet the basic requirements of the enterprise for the students' skills. Based on the platform of project-based postgraduate training mode, the disadvantages of the traditional training mode can be solved only by the cooperation between the school and the enterprise. And taking the project as the guidance can make the school, tutor and enterprise get what they need, and stimulate the students' practical interest and subjective initiative, so that the cultivation of practical ability of professional degree graduate students will not become empty talk, and the gold content of professional degree will be improved. Secondly, in order to meet the training purpose of professional degree postgraduates, we should appropriately increase the proportion of teachers with engineering practice experience when expanding the team of graduate tutors. We can recruit doctors with horizontal research background, or reduce the degree requirements of recruiting teachers, and recruit masters and senior engineers with many years of working experience in enterprises as professional degree postgraduates We have a reserve of teachers. In addition, in the employment of professional degree graduate tutors, schools should also give full consideration to the particularity of professional degree graduate training, and focus on the index of practical ability in the employment qualification, so as to be different from the employment conditions of academic degree graduate tutors. In addition to the above two core connotations, compared with other school enterprise joint training modes, the project cooperation mode has its own characteristics. In the construction process, it not only follows the general principles of constructing practical postgraduate training mode, but also fully considers the following principles:

\subsection{Increase the Encouragement of Enterprises}

The current school-enterprise cooperation is mainly the unilateral initiative of the school. The school hopes to continuously improve its educational level through teaching reforms to cultivate students in line with the development needs of the enterprise. However, the cultivation of high-level talents cannot be separated from the cultivation of hands-on practical ability. The real practical ability can only be trained on the technical post in the enterprise. Now, One of the main problems we are facing now is that we can't find suitable companies to cooperate with professional graduate students. School-enterprise cooperation to implement and deep into the line, the first thing that must be solved is the core problem that the company cares about, because the company itself has the fundamental pursuit of maximizing benefits, and the current cooperation model between the company and the school has not significantly increased the benefits of the company. As a result, enterprises are not very enthusiastic about participating in school-enterprise. In response to this problem, the country needs to give vigorous support on the legal and policy level. On the one hand, the state can introduce relevant laws to stipulate that enterprises have the obligation to participate in school-enterprise cooperation and jointly cultivate talents with schools. For example, a certain number of professional graduate students are allowed to enter the prescribed enterprises for practice within a specified period of time, and the state regularly supervises, rewards and accounts for the units that provide practice opportunities. The state can also formulate some preferential policies for enterprises that carry out school-enterprise cooperation, such as appropriately reducing taxes or increasing investment, etc. Through national laws and policies to increase the motivation and enthusiasm of enterprises in school-enterprise cooperation. On the other hand, the state can also provide certain financial compensation for the damage of some instruments and equipment that may be caused by students in the practice of applying professional theoretical knowledge. In addition, schools should also strengthen the education of intellectual property law for professional graduate students, so that students can fully realize the importance of protecting intellectual property rights of enterprises and hold students accountable for infringing intellectual property rights.

\subsection{Establish a New School-enterprise United Organization}

Under the current school-enterprise cooperation model, schools are only responsible for cultivating students' basic knowledge, while enterprises are only responsible for providing places for practice. Therefore, the training process of professional graduate students is divided into two independent stages, and the cooperation between schools and enterprises cannot promote and complement each other.

In order to further deepen the cooperation between the school and the enterprise, it is possible to consider the establishment of a special school-enterprise joint organization by both the school and the enterprise, which is responsible for the training of professional postgraduates, or jointly establish a school-enterprise joint laboratory. The school-enterprise joint laboratory is not focused on the research of basic theoretical knowledge and the publication of academic papers, but focusing on the practical problems faced by enterprises in the process of development, promoting scientific and technological innovation of the enterprise and bringing economic benefits. This new type of school-enterprise joint organization is jointly managed by the school and the enterprise. The school dispatches outstanding teachers in various disciplines and the enterprise dispatched engineers responsible for research and development to form a team of instructors. The supervising faculty can set up different research directions according to the research direction and actual situation, assign students to different tutor teams according to their research interests and expertise, and then the supervising faculty team will plan the postgraduate courses for different research directions. In order to ensure the effect of 
training, the planning of training courses should increase the proportion of credits for practical ability courses and reduce the proportion of credits for subject basic knowledge courses.

\subsection{Take Engineering Project as Carrier}

Under the current school-enterprise cooperation mode, professional postgraduates often just complete simple and scattered tasks when participating in practice, and there is no specific support carrier to enable students to solve practical problems in a comprehensive and systematic manner. In order to improve the training quality of professional postgraduates, practical ability training of professional postgraduates should be carried out with actual engineering projects as the carrier, so that school-enterprise cooperation can have a common focus. Engineering projects can be topics or product research and development projects proposed according to the needs of the enterprise. The professional graduate students received can be assigned to different engineering projects, or they can be assigned to different links of an engineering project for division of labor and cooperation, the instructor team conducts relevant teaching research on various problems that may arise in the engineering project. On the one hand, learning and practice can be integrated, and students can be guided to learn knowledge in practice and participate in practice better through learning knowledge. In this way, theoretical learning and practical exercise can promote each other. On the other hand, actual engineering projects often involve the intersection of multi-disciplinary contents. Participating in actual engineering projects also avoids the limitations of the traditional mode of teaching students' ability due to a single subject. During the postgraduate study, students must complete at least one engineering project under the guidance of the instructor team, and complete the graduation thesis based on the engineering project. The research results and patents applied by students in the practice process can be owned by the enterprise, and the intellectual property rights of the paper written by students are owned by the school. The instructor team will conduct a summary evaluation of the students based on the prospective application and completion of the engineering project.

\section{Conclusion}

School-enterprise cooperation is an important means to cultivate professional postgraduates, and improve students' innovation ability and practical ability. The school-enterprise cooperation model not only leverages the advantages of schools and enterprises in cultivating talents, but also provides more possibilities for the country to train high-level talents with practical ability. In order to make up for the defects of the current school-enterprise cooperation mode, this paper proposes a new school-enterprise cooperation mode by taking engineering project as the carrier. This training model can significantly increased the participation of professional graduate students in engineering projects, which is conducive to better achieving the school's talent training goals and increasing the employment rate of students. It also improves the enthusiasm of enterprises to participate, and makes a contribution to the technological innovation. At the same time, the students have improved their practical ability and work experience. After graduation, some students are more willing to stay in the internship or participate in the practice of the enterprise work, solved their own employment problems, and truly realized the "three wins". In the future, from the perspective of new engineering and large-scale engineering, we will sort out the school enterprise collaborative training mode of high-level applied talents and the background of the times, and put forward a high-quality education path based on multiple collaboration, internal -- external integration, complementary advantages, and integration of learning -research.

\section{Acknowledgements}

This work is supported by the Postgraduate Education Quality Improvement Project of Shandong Province (No. SDYKC19064).

\section{References}

[1] Zhang Yongze, Liu Xiaoguang, Dong Weichun. Exploration of project-based school enterprise collaborative training mode for professional degree postgraduates. Academic degrees and graduate education, 2014 (06): 8-12.

[2] Ou Shifeng, Li Zuohong, Wei Jing. Problems and corresponding improvement measures of professional degree postgraduate training. Education and teaching forum, 2016 (35): 224-225.

[3] Fan Xiaodong, Le Tao. Exploration and practice of innovative ability training mode for biology postgraduates -- Based on tripartite collaborative education mode. Education and teaching forum, 2021 (03): 105-108.

[4] He Xiaoliang, Jiang Zhilong, Liu Cheng, Kong Yan, Yu Lin. Main problems and countermeasures of postgraduate training mode of optical engineering. The science education article collects, 2020 (07): 85-87.

[5] Zhao Jinmei, Li Guang, Xie Yanfei, Chen guopeng, Lu Jia, Ma min. Reform and discussion on the training mode of full-time forestry postgraduates -- Taking Gansu Agricultural University as an example. Journal of higher education, 2020 (22): 20-22.

[6] Zhang Huaqiang, Wang Xinsheng, Shi Hongbo, Meng Shujun. Reform and practice of training system for applied talents with professional degrees. Journal of higher education, 2020 (01): 156-158.

[7] Liu Jing. Research on the mechanism of full-time engineering master professional practice under the mode of industry education integration. Industry and information technology education, 2019 (07): 30-34.

[8] Long Zhiqiang, Hu Hailin. Discussion on the training mode of full-time Mmaster of engineering. Contemporary education research and teaching practice, 2019 (11): 60-62.

[9] Cai binqing, Wu Renhua, Chen Qun. Analysis on the demand and mode of professional degree postgraduate training for industrial reform. Education review, 2019 (04): 87-91. 
[10] Xu Hong. A comparative study on the postgraduate training mode between China and the United States. Chengdu: Sichuan University Press, 2010: 34.

[11] Lei Zhengguang. Three aspects of German dual system model and some experiences that can be used for reference. Foreign education materials, 2000 (1): 78-80.

[12] Hu Haiqing. Institutional analysis on opportunistic behavior of enterprises in talent training of domestic university cooperation. Higher education research, 2014 (1): 61-67.

[13] Zhang Lanhong, He Jiangqiang, Shi Jun, Yang Ye. Exploration and practice of professional degree postgraduate training mode based on school enterprise collaborative innovation. Journal of higher education, 2020 (15): 37-40

[14] Zhang Xiaojie, Jin Ruojun, Li Jiyuan, Wang Rui, Zhou Xing, Shen Jianxin. Exploration and practice of graduate education of electrical engineering. Chinese Journal of electrical engineering, 2020, 40 (16): 5071-5079.

[15] Ou Shifeng, Li Zuohong, Gao Ying. Discussion on new training mode of school enterprise cooperation for professional postgraduates. University education, 2017 (09): 174-176. 